\title{
Introduction of Innovative Equipment in Mining: Impact on Occupational Health and Safety
}

\author{
Bryan Boudreau-Trudel $^{1}$, Sylvie Nadeau ${ }^{1}$, Kazimierz Zaras ${ }^{2}$, Isabelle Deschamps ${ }^{3}$ \\ ${ }^{1}$ Department of Mechanical Engineering, École de technologie supérieure, Montréal, Canada \\ ${ }^{2}$ Department of Management, Université du Québec en Abitibi-Témiscamingue, Rouyn-Noranda, Canada \\ ${ }^{3}$ Department of Mathematics and Industrial Engineering, École Polytechnique de Montréal, Montréal, Canada \\ Email: boudreab@uqat.ca, sylvie.nadeau@etsmtl.ca, kazimierz.zaras@uqat.ca, \\ isabelle.deschamps@polymtl.ca
}

Received 19 February 2013; revised 2 March 2013; accepted 9 March 2014

Copyright (C) 2014 by authors and Scientific Research Publishing Inc.

This work is licensed under the Creative Commons Attribution International License (CC BY).

http://creativecommons.org/licenses/by/4.0/

(c) (i) Open Access

\begin{abstract}
Occupational health and safety in mining has clearly improved in developed countries over the past twenty years, but accidents and illness still occur with unacceptable frequency. The arrival of new mining equipment, bigger, more powerful and complex and requiring a higher skill level appears also to increase certain specific risks of accident and work-related illness. The objective of this paper is to examine the impact of new equipment on occupational health and safety in underground mining. The injury rate associated with eight equipment introduction projects was examined. The results show clearly that the introduction of new equipment with technological innovations does not automatically reduce the injury rate. The new equipment may even generate a higher injury rate than the equipment it replaced. Ergonomic deficiencies were noted in some of the new equipment. We suggest that future research focus on identifying the mechanisms and conditions that determine injury rate following the acquisition of innovative as means of improving occupational health and safety in mining. Successful implementation of new mining equipment appears to depend on the specific conditions of use.
\end{abstract}

\section{Keywords}

Innovation; Mining Equipment; Occupational Health and Safety; Mines

\section{Introduction}

Over the past decade, we have witnessed a mining boom that has led businesses to venture into markets in which

How to cite this paper: Boudreau-Trudel, B., et al. (2014) Introduction of Innovative Equipment in Mining: Impact on Occupational Health and Safety. Open Journal of Safety Science and Technology, 4, 49-58. 
an increasing number of players are trying to differentiate themselves. As a result of this expansion, the mining industry now faces a serious shortage of qualified workers. Concurrent with this challenge are rising expectations of workers and society as a whole with regard to occupational and health safety (OHS).

Even though accidents and occupational illnesses continue to occur with unacceptable frequency [1], OHS in mining has clearly improved in developed countries over the past twenty years. For example, in the province of Québec (Canada) the injury rate was 15.0 per 100 workers per year in 1993 and has since dropped to 3.5 in 2013 [2].

The improvement of safety in mining is due to a host of factors, including modular training programs, better systems design, and technical advances in mining methods and equipment [3]. Many physically demanding manual tasks are now being carried out with mechanical devices, the operation of which is increasingly becoming semi-automated [4] [5].

\section{Problem}

The arrival of new bigger, more powerful and more complex mining equipment requiring a higher skill level appears also to introduce certain specific risks of accidents and work-related injury or illness. These are due to multiple factors such as reduced visibility and increased noise and vibration [6]-[10].

This has been demonstrated in a study by [11] showing that mining accidents and incidents in the United States and New Zealand are now associated primarily with machinery (respectively $34 \%$ and $18 \%$ ) and powered haulage (respectively $29 \%$ and $36 \%$ ). The study by [1] shows that over $30 \%$ of all equipment-related fatalities in mining in the USA during the period 1995-2005 involved haul trucks (22.3\%) and front-end-loaders (8.5\%). Among the 562 serious accidents (fatal or causing permanent disability) occurring over the period 2000-2007 in the US mining industry, bolting machines, haul trucks and front-end loaders are the most frequently involved mobile machines [12].

These statistics lead some researchers to conclude that new mining equipment technology changes the nature of mining tasks, which may lead to new hazardous situations if the new activity is not carefully analysed, properly understood and taken into due consideration [13]. Even though the high proportion of accidents involving equipment does not lead directly to the conclusion that the changes in the nature of the tasks are the cause, this is an hypothesis that can't be rejected and should be examined, since it is consistent with current knowledge in human factors engineering.

The present article is focused on characterizing the impact that introducing innovative equipment may have on OHS in the mining industry.

\section{Methodology}

For the purposes of the present study, we measured the impact of eight equipment introduction projects on OHS in a North-American underground goldmine, using frequency of injury as the performance indicator. We choose this indicator because it allows comparison of current and past performance with a certain degree of confidence [14]. Our oldest equipment introduction project took place in 2005 and our most recent in 2011. We limited our research to permanent employees of the selected mine. Mechanics, supervisors and contractors were not included in our analysis. Measurements were performed over the 12-month period following each technological introduction in order to eliminate potential biases due to variations between different periods of the year [15]. We compared the OHS performance associated with each project to the corresponding performance recorded for the preceding 12-month period with the supplanted technology.

\subsection{Equipment Introduction Projects}

Table 1 below summarizes the eight projects under study. Each of these vehicles cost nearly \$1 million, except for the new scissor-lifts in project 8 , which cost about \$350,000 per unit. Project 1 involved the deployment in 2010 of a semi-automated bolter from manufacturer A. This machine installs the screen that stabilizes the field being mined. The operator (seated) uses a joystick to direct the two booms. Before its introduction, the company used two different groups of bolters (both provided by manufacturer B) with platform lifts, namely the standard groups in projects 1 and 1.5, which included respectively seven and two machines. The performance of the innovative group was compared to those of both standard groups. In the case of project 1.5, it should be noted that 
Table 1. Summary of the ten equipment-upgrading projects under study.

\begin{tabular}{|c|c|c|c|}
\hline \multirow{2}{*}{ Project } & \multirow{2}{*}{ Category/type of equipment } & \multicolumn{2}{|c|}{ Number of units } \\
\hline & & Innovative $^{\mathrm{a}}$ & Standard ${ }^{\mathrm{b}}$ \\
\hline 1 & Bolter/semi-automated & 1 & 7 \\
\hline 1.5 & Bolter/semi-automated & 1 & 2 \\
\hline 2 & Bolter/new generation & 2 & 2 \\
\hline 3 & Long-hole drill/new generation & 1 & 1 \\
\hline 4 & Truck/30 ton & 3 & 10 \\
\hline 5 & Truck/50 ton & 2 & 3 \\
\hline 6 & LHD/new generation & 2 & 6 \\
\hline 7 & LHD/cab + air conditioning & 6 & 4 \\
\hline 8 & Scissor lift/new generation & 2 & 8 \\
\hline
\end{tabular}

${ }^{\mathrm{a} I n t r o d u c e d ~ w i t h i n ~} 12$ months of the first introduction of this type of equipment; ${ }^{\mathrm{b}}$ Included in the group used to measure productivity before the introduction of the new technology.

the innovative and standard groups were introduced less than two years apart.

Project 2 involved the deployment of two new-generation bolters acquired in 2009 from manufacturer B. The intention of their novel design was to minimize physical effort and fatigue. The OHS record associated with their use was compared with that of two units of the equivalent model obtained from this manufacturer more than 12 years earlier. The bolters in both groups are equipped with platform lifts.

Project 3 involved the acquisition in 2010 of a flexible electro-hydraulic long-hole drilling rig. Purchased from manufacturer A, this remote-controlled drill is used for large-scale production drilling. It was compared to a drill obtained from manufacturer $C$ and dating back to early 1990, twenty years of technological improvement and new features thus separating the two drills.

Project 4 involved the arrival of a fleet of three 30-ton trucks in 2010 to replace some of the ten 50-ton trucks obtained from manufacturer A. The new trucks were purchased from manufacturer $\mathrm{D}$. The company directors were disappointed with the productivity performance of the 50-ton trucks and therefore decided to replace them with new trucks with a smaller load capacity.

Project 5 involved the arrival in 2005 of two 50-ton trucks to replace their three 30-ton trucks. Both trucks were obtained from manufacturer A. By using trucks with a bigger loading capacity, the company hoped to reduce vehicle traffic in the galleries.

Project 6 involved the introduction of two 8-yard load-haul-dump (LHD) vehicles in 2009. The basis of comparison was a fleet of six old LHDs. Both new and old were acquired from manufacturer A, but are of different generations. The new vehicle has a newly redesigned operator cabin that is supposed to provide easier access, improved visibility, efficient air conditioning, and lower noise level.

Project 7 involved the introduction in 2007 of six new 8-yard LHDs obtained from manufacturer A. These were the first LHDs with cabin and air-conditioning to be used in this mine. The basis of comparison was a group of four of the older 8-yard LHDs from manufacturer A.

Project 8 involved the deployment in 2010 of two new scissor-lifts introduced that year by manufacturer B. These new platforms were selected for their increased speed and for technical improvements such as opening on the side. They were compared with a group of eight scissor-lifts obtained from manufacturer F.

\subsection{Performance Indicator}

We searched the mining company databases for OHS events involving the vehicles in the different groups being compared. Injury rate (IR) was used as the indicator of OHS performance. Incidence was calculated for the innovative equipment during the 12-month period following the first implementation, and for the standard equipment during the 12-month period preceding the first implementation of the innovative equipment.

The IR is preferable to the real number of accidents because it indicates the number of accidents occurring for 
a fixed number of employees or employee-hours. This allows comparison to past performance with a certain degree of confidence [14]. The literature is replete with justification for its universal and standardized use [9] [11] [16]. The IR represents the number of injuries that occurred per 200,000 employee-hours worked, calculated as follows:

$$
\text { IR }=\frac{\text { Number of injury occurrences }}{\text { Total hours worked by employees }} \times 200000
$$

The calculation is based on 200,000 hours in North America and on 100,000 hours in Europe. The average number of hours worked by 100 workers in North America is about 200,000 (100 X 40 hours X 50). Because our study focuses on the impact of new equipment, we replaced the "total hours worked by employees" by the "total hours of equipment use" for each project.

\section{Results}

Table 2 below summarizes the results of our study. Only half of the projects provided any improvement of the IR indicator. Improvement was noted in the case of the semi-automated bolters (projects 1 and 1.5), the new drills (project 3), and the replacement of the 50-ton trucks by the new 30-ton trucks (project 4). Among the remaining projects, the arrival of new equipment actually increased the IR, with the exception of project 5 (no effect of truck loading capacity on IR).

In order to provide more information on the impact of the innovative equipment, several excerpts from injury reports associated with some of the projects (bolters, trucks and LHDs) are listed in the following section. We selected these projects because the reports provided valuable insight into specific aspects of OHS risks in mining.

\subsection{Bolters (Projects 1 and 1.5)}

The innovation in projects 1 and 1.5 is a semi-automated bolter with two booms (Figure 1(a)), one for lifting and holding the screen and the other for drilling and inserting bolts, allowing operators to stay in the cabin and control both booms with a joystick. To compare, we are examining the IR associated with a machine which requires stepping up and down a flight of steps to the platform, the manual handling and holding of screens, and exposes workers from rocks falling from the gallery roof (Figure 1(b)). As shown in Table 3 below, many of the injuries occurred while handling screens or stepping down from the platform. Both activities have been almost eliminated with the arrival of new bolter. There is no longer a flight of steps, and the handling of screens is now very limited (see Figure 1). The elimination of these actions explains why the IR went from 140.85 (project 1) and 170.29 (project 1.5) to 68.97 with the introduction of the new bolter.

\section{Table 2. Comparison of innovative and standard mining equipment in terms of injury rate.}

\begin{tabular}{|c|c|c|c|c|c|c|c|}
\hline & \multirow[b]{3}{*}{ Project } & \multicolumn{6}{|c|}{ Group } \\
\hline & & \multicolumn{3}{|c|}{ Innovative } & \multicolumn{3}{|c|}{ Standard } \\
\hline & & Hours Worked & Number of injuries & IR & Hours Worked & Number of injuries & IR \\
\hline \multirow{3}{*}{ Bolters } & 1 & 2900 & 1 & 68.97 & 19,880 & 14 & 140.85 \\
\hline & 1.5 & 2900 & 1 & 68.97 & 7047 & 6 & 170.29 \\
\hline & 2 & 6715 & 7 & 208.49 & 4664 & 4 & 171.53 \\
\hline Drills & 3 & 2406 & 1 & 83.13 & 1662 & 1 & 120.34 \\
\hline \multirow{2}{*}{ Trucks } & 4 & 4486 & 0 & 0.00 & 33,389 & 12 & 71.88 \\
\hline & 5 & 5020 & 0 & 0.00 & 9555 & 0 & 0.00 \\
\hline \multirow{2}{*}{ LHDs } & 6 & 3573 & 3 & 167.93 & 22,862 & 6 & 52.49 \\
\hline & 7 & 19,215 & 7 & 72.86 & 12,657 & 3 & 47.40 \\
\hline Sc. Lifts & 8 & 1454 & 2 & 275.10 & 4130 & 2 & 96.85 \\
\hline
\end{tabular}




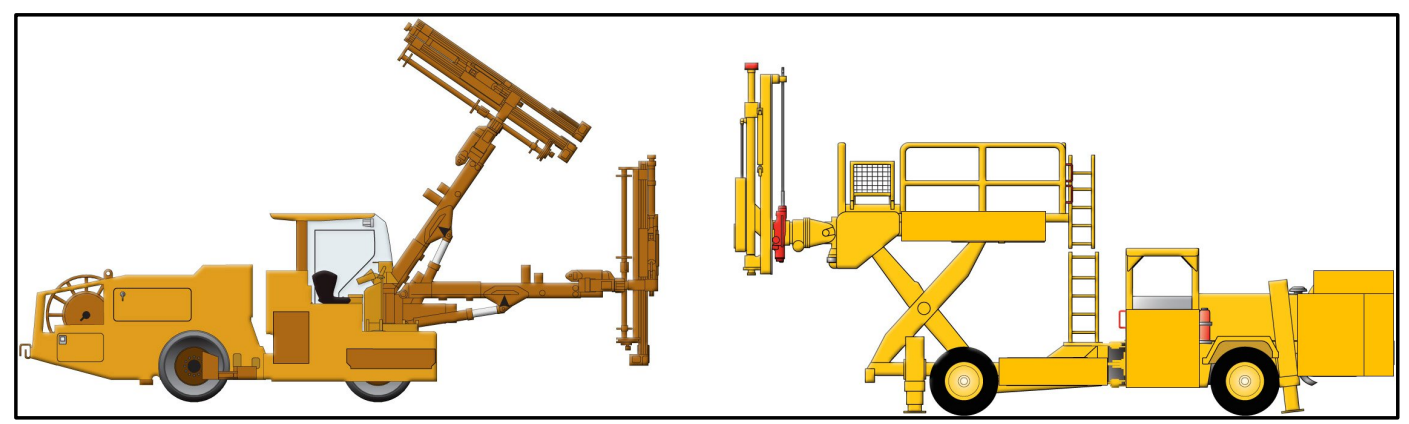

(a)

(b)

Figure 1. Semi-automated bolter VS standard bolter.

Table 3. Excerpts from reports of injuries involving bolters.

\begin{tabular}{|c|c|c|c|}
\hline \multicolumn{4}{|c|}{ Bolters } \\
\hline Event\# & Project 1 - Standard & Event \# & Project 1.5 - Standard \\
\hline 1 & $\begin{array}{l}\text { While installing a screen on the gallery roof, a small } \\
\text { rock slipped onto the screen and struck my finger. }\end{array}$ & 1 & $\begin{array}{l}\text { While stepping down from the BO to the floor, } \\
\text { my foot slipped near the joint (center) and } \\
\text { I fell on my ribs on my right side. }\end{array}$ \\
\hline 2 & $\begin{array}{l}\text { I was handling a screen to install it on the boom when } \\
\text { I felt lower back pain on the right side. }\end{array}$ & 2 & $\begin{array}{l}\text { While grabbing a screen on the side of } \\
\text { the bolter, I felt a pain in my back. }\end{array}$ \\
\hline 3 & $\begin{array}{l}\text { On the BOXXX, I stumbled on a 5-gallon oil } \\
\text { container and jammed my left thumb. }\end{array}$ & 3 & $\begin{array}{l}\text { While handling a screen, I felt a pain at the } \\
\text { base of the neck on the left side. }\end{array}$ \\
\hline 4 & $\begin{array}{l}\text { While attaching a sheet of screen to the ceiling, a } \\
\text { rock fell on my forearm (size of rock: } 4 " \text { X } 4 " \text { ) }\end{array}$ & & \\
\hline 5 & $\begin{array}{l}\text { While bolting my ceiling with the BOXXX, I raised my } \\
\text { platform and was in the browl at a height of } 6.5 \text { m. I banged } \\
\text { my head on a rebar on the roof, hurting my neck badly. }\end{array}$ & & \\
\hline 6 & $\begin{array}{l}\text { While stepping down from the bolter, my right foot slipped } \\
\text { and my entire weight came down on my left ankle. }\end{array}$ & & \\
\hline
\end{tabular}

\subsection{Trucks (Project 4)}

Table 4 shows excerpts from injury reports associated with the standard truck group in project 4 . Analysis of these reports reveals that the big 50-ton trucks caused visibility problems for the operators. Operators were unable to see big rocks or holes on road and drove over them, often sustaining injury to the back or head as a result (events 2, 3, 6, 8). These injuries appear to have been exacerbated by the additional problem of the level of the suspension of seats, as well as insufficient headroom inside the cabin. These were not the only injuries associated with the ergonomics of the 50-ton trucks. Events 1, 4, 5, 7 and 9 appear to have similar causes. All of these concerns appeared to be resolved completely following the introduction of the new 30-ton trucks, since no injuries occurred over the subsequent 12-month period (Table 2).

\subsection{LHDs (Project 7)}

The purpose of project 7 was to introduce the first LHDs with cabin and air conditioning, primarily to provide safer and better working conditions to operators. The cabin provides protection against dust and falling rocks, while the air conditioning provides a cooler and more comfortable working environment. However, analysis of the reports reveals that the introduction of these new LHDs also brought new risks for the operators (Table 5). The cabin seems to have some design problems, since operators banged their heads on the ceiling (events 1 and 2) and their bodies collided with different parts of the inside of the cabin (events 3, 5 and 6). As a result of these ergonomic deficiencies, the IR went from 47.40 to 72.86 following the arrival of the LHDs equipped with cabin and air conditioning. 
Table 4. Excerpts from reports of injury involving trucks.

\begin{tabular}{|c|c|}
\hline \multicolumn{2}{|l|}{ Trucks } \\
\hline Event\# & Project 4-Standard \\
\hline 1 & While climbing onto the side of the 50-ton truck to fuel up, I felt a deep pain on the side of my right knee. \\
\hline 2 & $\begin{array}{l}\text { I drove the truck over a rock (not seen because it was in a blind spot) in a curve and my body hit the inside } \\
\text { of the CAXXX. Pain in the back, neck and right knee. }\end{array}$ \\
\hline 3 & I drove over a rock and my head hit the cabin ceiling violently. Bad neck pain. \\
\hline 4 & $\begin{array}{l}\text { While stepping down from the truck, I stepped on a rock with my left foot and twisted my ankle and felt } \\
\text { an intense strain in the calf muscle. }\end{array}$ \\
\hline 5 & While stepping down from the truck, the door closed on my thumb. Crushed right thumb, nail turned black. \\
\hline 6 & $\begin{array}{l}\text { While negotiating a turn, employee } X \text { drove the } 50 \text {-ton truck over a } 2^{\prime} \times 2 \text { ' rock, banged his head against the } \\
\text { cabin ceiling and went into the front wall near the electric bay. Pain in the neck and shoulders. }\end{array}$ \\
\hline 7 & While getting into the truck, I grabbed the handle and felt a burning pain in my right shoulder. \\
\hline 8 & $\begin{array}{l}\text { Driving the CAXXX with the seatbelt attached, I entered level X and drove over a hole, giving me a jolt in } \\
\text { the lower back and top of the neck because of the belt. }\end{array}$ \\
\hline 9 & $\begin{array}{l}\text { While trying to hang up the microphone of the radio in the CAXXX, I cut my right index finger on the rack } \\
\text { that holds the microphone. }\end{array}$ \\
\hline
\end{tabular}

Table 5. Excerpts from the reports of injuries involving LHDs.

\begin{tabular}{|c|c|}
\hline \multicolumn{2}{|r|}{ LHDs } \\
\hline Event\# & Project 7-Innovative \\
\hline 1 & I drove the scoop over a rock and banged my head against the cabin ceiling. I felt a crackle in my neck. \\
\hline 2 & $\begin{array}{l}\text { The road to my drift was in very poor condition and I drove over a hole and banged my head against } \\
\text { the ceiling of the cabin. I lost my helmet and I since have neck pain and headaches. }\end{array}$ \\
\hline 3 & $\begin{array}{l}\text { While picking up a big rock, it fell from the bucket [shaking the cabin] and I struck my right } \\
\text { elbow against the hinge of the dash of the LHDXXX. }\end{array}$ \\
\hline 4 & While getting out of the LHD I stepped on a loose rock and twisted my left ankle \\
\hline 5 & My knee struck the cabin fire extinguisher support while I was coming down from the scoop. \\
\hline 6 & While coming down from the scoop, I banged my left elbow on the wing of the scoop. \\
\hline
\end{tabular}

\section{Discussion}

Since our OHS performance indicator is the injury rate, reliance on equipment operators to report their injuries represents the principal limitation of our research. Minor injuries might have been underreported. In order to analyse our results within a reasonable time, we focused on a 12-month period. This is sufficient to allow confirmation of internal validity of the results. Other indicators could be used, such as severity of injuries based on workdays lost, as used by [9] [17]. However, the mine in which we performed our study does not keep such records. Injury rate is a well-recognized indicator in the field [9] [11] [16], and will facilitate the reproduction of our method in future research.

The focus of our study was the impact of new and innovative production equipment on OHS, but in the mining industry as in other businesses, the motivation for investing in such equipment may be based on a broader range of considerations. One of these is of course improvement of productivity. In the current context (a mining boom since the beginning of this century), mining companies are trying to attract investors by maintaining a cost structure with operating costs as low as possible. A favoured approach has been to purchase new equipment with bigger capacity in order to reduce the number of vehicles and hence of operators. This was the aim of project 5 in particular with the introduction of 50-ton trucks to replace the existing 30-ton truck fleet. However, the 50-ton trucks did not bring the expected gain in productivity, and the company decided to go back to 30 -ton trucks. Al- 
though motivated primarily by productivity, this decision led to a lower IR and hence an improved OHS performance.

On the other hand, some projects (e.g. project 7) that were intended to upgrade working conditions, ended up causing an increase in IR. The new fleet of LHDs with cabin and air conditioning was supposed to provide a better and safer working environment, but also brought new risks to operators because of deficient cabin design. This observation corroborates much previous research on load-haul-dump vehicles showing that the cabins of such vehicles suffer from poor ergonomic design [7] [8] [12] [13] [18] [19]. Operators' visibility and posture are often cited as major concerns in these studies. Many injuries related in our study confirm the visibility concern (in addition to cabin headroom), these resulting from operators driving over rocks or holes and banging their heads against the cabin ceiling.

The purchase of semi-automated bolter (projects 1 and 1.5) was intended essentially to reduce or eliminate specific risks for the operators (the steps up to the platform, handling of mesh, exposure to rock fall). The goal was achieved in this case, as proven by the decrease in the IR. In the mining industry, some actors assume that automated technologies are unreliable [20] [21]. This perception appears to be a major barrier to the spread of automated equipment in underground mining. Automation usually brings many benefits. It offers a safer working environment by removing the operators from hazardous situations (as our results show), enhances precision (e.g. in drilling), allows mining in spaces not previously accessible to humans, and reduces the manning of equipment.

The results of the introduction of a new non-automated bolter (project 2) show that bolters still have a high IR. An explanation for these results is suggested in a preliminary ergonomic study of a bolting machine and a drill [22], in which many ergonomic problems were noted in association with operator discomfort, affecting in particular the torso, the head and the feet. Limited cabin space, especially headroom, was another concern raised in that study.

The new and bigger equipment also led to collateral accidents. We did not measure their frequency in our study, but they should be taken into consideration. Because of their size, particularly of the 30-ton and 50-ton trucks and the LHD, the tires of these mining vehicles are huge. These tires leave deep tracks in the paths, which sometimes become problematic for small vehicles such as tractors and pick-up trucks, to name just two. These smaller vehicles can even overturn when they pass over tracks left by the big vehicles, which is obviously a very dangerous occurrence for workers seated inside them. In the case of this type of accident it is difficult to identify the culprit since several vehicle types use the same tires. But there is no doubt that these big vehicles create risks for workers using smaller vehicles.

Several studies show that mining companies around the world prefer to purchase equipment from manufacturers instead of developing it themselves [23]-[27]. In fact, investment in technological development in the mining sector is in decline [27]. Most mining companies now appear to rely on keeping abreast of technologies being developed by third parties, in particular equipment manufacturers, and acquiring these technologies as the need arises [24] [26]. In-house R \& D expenditure in the mining sector as a whole is small in comparison with other sectors [27]. R \& D budgets reflect the widespread consolidation of mining companies over the past decade as a result of globalization. No more than $10 \%$ of the annual cash flow is spent on R \& D in the mining industry, compared with $51 \%$ at the pharmaceutical company Pfizer Inc. and 37\% at Microsoft [28]. Among Canadian mining companies, expenditure on R \& D in 2011 was less than $1 \%$ of gross income [29]. The Canadian mining company Osisko stated in a published document [30] that from 2001 to 2010 the Canadian mining industry as a whole spent more on R \& D (\$16.8 billion) than did the pharmaceutical industry ( $\$ 12.2$ billion). However, this expenditure was primarily for exploration and not for the development of new machinery or processes needed in extraction. Nonetheless, we cannot leave untold an important research network, which was born in Canada in January 2014, the Ultra-Deep Mining Network (UDMN). One of the purposes of the UDMN, a $\$ 46$ million business-driven network, is to generate fruitful collaborations between mining industry and research entity in order to answer critical challenges relate to resource extraction in ultra-deep mining environments [31].

Globalization has also had an impact on mining equipment manufacturers, which are now multinational corporations. Their product lines are designed to satisfy as many potential clients as possible around the world. This generalist approach makes it more difficult to adapt equipment to the particular needs of specific users. Rather than working with manufacturers to design equipment meeting these needs, mining companies prefer to purchase "from the warehouse". For vehicles that retail at a million dollars per unit, this practice is perplexing, es- 
pecially in view of results such as we observed. A reasonable compromise between costly, time-consuming inhouse R \& D and purchasing directly from the manufacturer's catalogue could be calling for tenders to meet technical specifications. Considering that multi-million-dollar orders for fleets of equipment are at stake, it is difficult to imagine such calls for tenders not motivating mining equipment manufacturers to share the cost of the required adaptations.

Our results show that new equipment sometimes brings improved IR and sometimes does not, even when improving IR was the principal motivation for the purchase. This irregularity demonstrates clearly that the acquisition of innovative mining equipment does not automatically improve operational safety. In view of this, we suggest that future research focus on identifying the mechanisms and conditions that are involved when the introduction of innovation does help to reduce the IR. Furthermore, the success of implementation of machinery with novel technology may also be influenced by numerous human factors [14] [21] [32] [33], of which the key ones remain to be identified and measured.

\section{Conclusions}

The main finding of our study is a clear demonstration based on an objective indicator that the acquisition of innovative equipment by the participating underground mining company did not automatically reduce the incidence of workplace injury. The example of the LHD purchase, expected to improve working conditions (with an air-conditioned protective cabin) but in reality having the opposite effect, shows that new equipment does not always meet expectations.

In summary, our results show that new equipment purchased directly from manufacturers may generate a higher IR than the old equipment and that new equipment still suffers from poor ergonomic design, and all this in spite of the very high cost of its acquisition.

Successful implementation of technological innovation requires more than just buying new equipment. It requires taking into account the environment in which the equipment will operate, the needs and characteristics of the operators involved, and also the expectations of the decision makers.

Our findings show the importance of identifying the mechanisms and conditions that determine the frequency of injuries following the acquisition of innovative equipment as means of improving $\mathrm{OHS}$ in the mining sector.

\section{Acknowledgements}

We thank the mining company and the participating employees for their precious time. We also thank the Fonds de recherche du Québec sur la nature et les technologies (FRQNT), the Fondation de l’Université du Québec en Abitibi-Témiscamingue (FUQAT), and École de technologie supérieure (ÉTS) for their financial support of our research. We are deeply grateful for the opportunity to carry out this study.

\section{References}

[1] Kecojevic, V., Komljenovic, D., Groves, W. and Rodomsky, M. (2007) An Analysis of Equipment-Related Fatal Accidents in U.S. Mining Operations: 1995-2005. Safety Science, 45, 864-874. http://dx.doi.org/10.1016/j.ssci.2006.08.024

[2] APSM (Association Paritaire pour la Santé et la Sécurité du Travail du SecteurMinier) (2013) Evolution of the Hours Worked (in Millions), the Frequency and the Severity on August 31st, 2013-Évolution des Heures Travaillées (en Millions), de la Fréquence et de la Gravité au 31 août 2013. http://aspmines.qc.ca/info-statistiques/

[3] MMSD (Mining, Minerals and Sustainable Development) (2002) The Story of North American Mining/Mineral. http://www.iisd.org/pdf/2002/mmsd_sus_profile.pdf

[4] Horberry, T., Burgess-Limerick, R. and Steiner, L. (2011) Human Factors for the Design, Operation, and Maintenance of Mining Equipment. CRC Press, New York.

[5] CEMI (Centre for Excellence in Mining Innovation) (2013) Mine Automation-A Vision of Our Future. Ultra Deep Mining Workshop, Sudbury, 12-13 June 2013.

[6] Kumar, S. (2004) Vibration in Operating Heavy Haul Trucks in Overburden Mining. Applied Ergonomics, 35, 509-520. http://dx.doi.org/10.1016/j.apergo.2004.06.009

[7] Eger, T., Salmoni A. and Whissel, R. (2004) Factors Influencing Load-Haul-Dump Operator Line of Sight in Underground Mining. Applied Ergonomics, 35, 93-103. http://dx.doi.org/10.1016/j.apergo.2003.12.002

[8] Eger, T., Salmoni, A., Cann, A. and Jack, R. (2006) Whole-Body Vibration Exposure Experienced by Mining Equip- 
ment Operators. Occupational Ergonomics, 6, 121-127.

[9] Coleman, P.J. and Kerkering, J.C. (2007) Measuring Mining Safety with Injury Statistics: Lost Workdays as Indicators of Risk. Journal of Safety Research, 38, 523-533.http://dx.doi.org/10.1016/j.jsr.2007.06.005

[10] Ouellet, S., Ledoux, É., Cloutier E. and Fournier, P.S. (2011) Conditions of Integration of the New Workers in the Mining Sector: An Exploratory Study-Conditions d’Intégration des Nouveaux Travailleursdans le SecteurMinier : une Étude Exploratoire (Version Corrigée). R-650, Institut de Recherche Robert-Sauvé en Santé et en Sécurité du Travail, Montréal.

[11] Ural, S. and Demirkol, S. (2008) Evaluation of Occupational Safety and Health in Surfaces Mines. Safety Science, 46, 1016-1024. http://dx.doi.org/10.1016/j.ssci.2007.11.010

[12] Ruff, T., Coleman, P. and Martini, L. (2011) Machine-Related Injuries in the US Mining Industry and Priorities for Safety Research. International Journal of Injury Control and Safety Promotion, 18, 11-20. http://dx.doi.org/10.1080/17457300.2010.487154

[13] Dhillon, B.S. (2010) Mine Safety: A Modern Approach. Springer, London.

[14] Karmis, M. (2001) Mine Health and Safety Management. Society for Mining, Metallurgy, and Exploration, Inc., Littleton.

[15] Dessureault, P.C. and Doucet, M. (2003) Evaluation of the Thermal Constraint Indicators in Deep Mining-Évaluation des Indices de Contrainte Thermique en Mines Profondes.R-350, Institut de Recherche Robert-Sauvé en Santé et en Sécurité du Travail, Montréal.

[16] MSHA (Mine Safety and Health Administration) (2013) Mine Injury and Worktime, Quartely. Yearly Reports, January-June 2013 (Preliminary). http://www.msha.gov/Stats/Part50/WQ/MasterFiles/MIWQ Master_20132.pdf

[17] Groves, W.A., Kecojevic, V.J. and Komljenovic, D. (2007) Analysis of Fatalities and Injuries Involving Mining Equipment. Journal of Safety Research, 38, 461-470.http://dx.doi.org/10.1016/j.jsr.2007.03.011

[18] Eger, T., Stevenson, J., Boileau, P.-É. and Salmoni, A. (2008) Predictions of Health Risks Associated with the Operation of Load-Haul-Dump Mining Vehicles: Part 1-Analysis of Whole-Body Vibration Exposure Using ISO 2631-1 and ISO-2631-5 Standards. International Journal of IndustrialErgonomics, 38, 726-738. http://dx.doi.org/10.1016/j.ergon.2007.08.012

[19] Eger, T., Stevenson, J., Boileau, P.-É. and Salmoni, A. (2008) Predictions of Health Risks Associated with the Operation of Load-Haul-Dump Mining Vehicles: Part 2-Evaluation of Operator Driving Postures and Associated Postural Loading. International Journal of Industrial Ergonomics, 38, 801-815. http://dx.doi.org/10.1016/j.ergon.2007.09.003

[20] Gustafson, A. (2011) Automation of Load Haul Dump Machines. Research Report, Luleå University of Technology.

[21] Lynas, D. and Horberry, T. (2011) Human Factor Issues with Automated Mining Equipment. The Ergonomics Open Journal, 4, 74-80. http://dx.doi.org/10.2174/1875934301104010074

[22] Roque, N., Nadeau, S. and Badri, A. (2014) Preliminary Ergonomics of a Bolting Machine and a Drill Used in Underground Mining. Accepted in November 2013. Gesellschaft für Arbeitswissenschaft, Munich, 12-14 March 2014.

[23] Statistics Canada (2002) The Innovation and the Use of High Technologies in the Sector of the Mining Extraction in Canada: Extraction of Metallic Ores-L'Innovationet l'Utilisation de Technologies de Pointe dans le Secteur de l'ExtractionMinière au Canada: Extraction de Minerais Métalliques, No 88F0006XIF2002013, Government of Canada.

[24] Hood, M. (2004) Advances in Hard Rock Mining Technology. Proceedings of the Mineral Economics and Management Society, 13th Annual Conference, 21-23 April 2004.

[25] Upstill, G. and Hall, P. (2006) Innovation in the Minerals Industry: Australia in a Global Context. Resources Policy, 31, 137-145. http://dx.doi.org/10.1016/j.resourpol.2006.12.002

[26] Yudelman, D. (2006) New Mining Technology. The Northern Miner.

[27] Bartos, P. (2007) Is Mining a High-Tech Industry? Investigations into Innovation and Productivity Advance. Resources Policy, 32, 149-158. http://dx.doi.org/10.1016/j.resourpol.2007.07.001

[28] Lasonde, P. (2006) Exploration the Life Blood of the Mining Industry. Presentation to Society of Economic Geologists Conference, Wealth Creation in the Mineral Industry, Integrating Science, Business, and Education, 14 May 2006, CD-ROM.

[29] Statistics Canada (2013) Business Enterprise Current Intramural Research and Development Expenditures as a Percentage of Performing Research and Development Company Revenues. http://www5.statcan.gc.ca/cansim/a26?lang=eng\&retrLang=eng\&id=3580211\&paSer=\&pattern=\&stBy Val=1\&p1=1\& p2=38\&tabMode $=$ dataTable\&csid

[30] Osisko. (2011) The Quebec Mining Industry: An Industry of the Knowledge, Creator of Wealth for the CommunityL’Industrie Minière Québécoise: UneIndustrie du Savoir, Créatrice de Richessepour la Collectivité.

http://www.minalliance.ca/pdfs/industrie-miniere-quebecoise-aout-2011.pdf 
[31] CEMI (Centre for Excellence in Mining Innovation) (2014) CEMI Awarded \$15 Million for Ultra-Deep Mining Network. https://www.miningexcellence.ca/?p=3095

[32] Trudel, B., Nadeau, S., Zaras, K. and Deschamps, I. (2012) The Impact of Technological Innovation on Productivity and OHS Performance in Mining. Nordic Ergonomics Society, Stockholm, 19-22 August 2012.

[33] Trudel, B. Zaras, K., Nadeau, S. and Deschamps, I. (2014) Introduction of Innovative Equipment in Mining: Impact on Productivity. American Journal of Industrial and Business Management, 4, 31-39.

http://dx.doi.org/10.4236/ajibm.2014.41006 